\title{
Long-Term Erosional Trends Along Channelized Salt Marsh Edges
}

\author{
James P. Browne ${ }^{1,2}$
}

Received: 20 February 2016 /Revised: 23 March 2017 / Accepted: 30 March 2017 /Published online: 21 April 2017

(C) The Author(s) 2017. This article is an open access publication

\begin{abstract}
Salt marshes provide important habitats for many species in the estuaries along the east and Gulf coasts of North America. With many species dependent on these coastal marshlands and extensive documentation that these marshlands are disappearing, a clear understanding of the mechanisms causing loss is critical. Much of the salt marsh was lost to reclamation and construction before these activities were curtailed circa 1970; however, losses due to other causes have continued and multiple hypothesized causes have been proposed, not all mutually exclusive. Yet it remains unclear whether there are legacy effects from the reclamation projects. When the edges of salt marshes are cut into, and gentle vegetated slopes are replaced by sharp edges adjoining deep water of $2 \mathrm{~m}$ or more, erosion could accelerate and could continue for many years. One method that may help shed light on the relative importance of the various causes of salt marsh erosion would be to compare the erosion rates of specific edges within a marshland that are exposed to particular conditions. We therefore used several sets of aerial photography spanning 84 years to track the changes at specific edge locations along marsh edges and then make comparisons between
\end{abstract}

Communicated by Carles Ibanez Marti

Electronic supplementary material The online version of this article (doi:10.1007/s12237-017-0245-y) contains supplementary material, which is available to authorized users.

James P. Browne

james.browne@stonybrook.edu

1 Department of Conservation and Waterways, Town of Hempstead, PO Box 180, Point Lookout, NY 11569, USA

2 Department of Ecology and Evolution, Stony Brook University, 650 Life Sciences Building, Stony Brook, NY 11794-5245, USA anthropogenically created edges and naturally created edges, including comparisons within use and width categories of navigational channels. Erosion rates were found to remain significantly higher on channelized edges than along otherwise similar wetland edges even several decades after modification. Likely reasons include the continued exposure of underlying layers that lack reinforcing plant root systems, vertical edges that are more vulnerable to undermining from wave action, and increased erosion related to altered tidal flows.

Keywords Spartina $\cdot$ Salt marsh $\cdot$ Navigational channels · Dredging $\cdot$ Erosion

\section{Introduction}

Wetlands serve as a valuable natural resource supplying may ecosystem services (Keddy et al. 2009), including roles as nurseries for thousands of species, as barriers protecting human infrastructure from storm surges, in the dissipation of wave energy, in denitrification, and as water filtration systems (Möller et al. 1999; Shriver et al. 2004; Cooper 2005; Zedler and Kercher 2005; Costanza et al. 2008; Feagin et al. 2010; Barbier et al. 2011, Fagherazzi 2014). Globally, wetlands have lost about half their area worldwide since the 1900 (Spiers 2001; Larsen et al. 2009; Keddy et al. 2009). Many mechanisms have proposed to explain the losses of salt marshes (Mendelssohn and McKee 1988; McKee et al. 2004; Edwards et al. 2005; Silliman et al. 2005; Mendelssohn et al. 2006; Alber et al. 2008; Ogburn and Alber 2006; Gedan et al. 2011; Deegan et al. 2007; Deegan et al. 2012), and it is unlikely that any single factor is the major cause of marsh loss throughout their geographic range. Even within a single bay, 


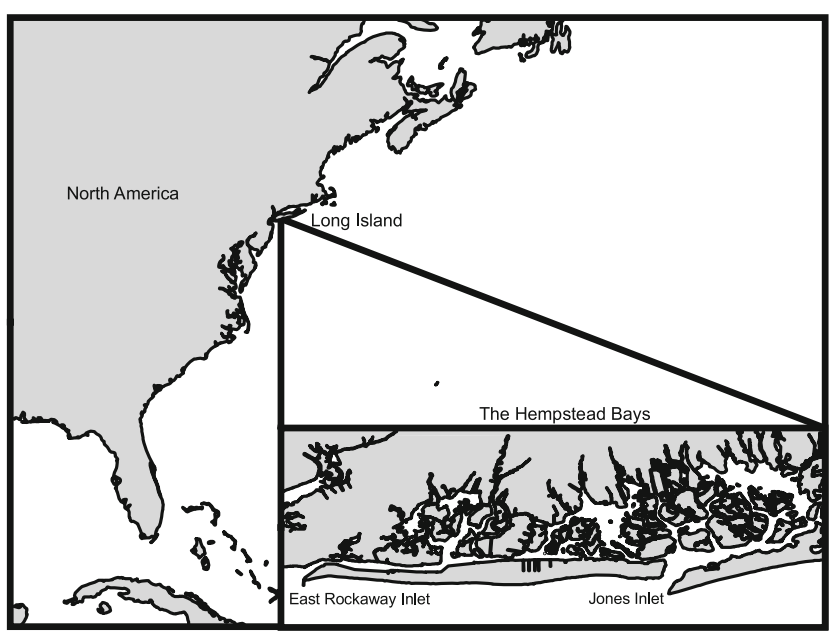

Fig. 1 The study area was located in Hempstead Bay, part of the South Shore Estuary of Long Island, NY, USA

different marshes may respond differently (Wigand et al. 2014).

Boat traffic is sometimes implicated in edge erosion (Zabawa and Ostrom 1980; Dorava and Moore 1997; Davis et al. 2009). However, many natural forces are also erosive, including waves formed by winds over long stretches of water (Pye 1995; Schwimmer 2001; Leonardi et al. 2016), but these waves can be larger when water becomes deepened by sealevel rise, excessive dredging, or other reasons. Tidal currents can induce meander patterns of erosion and redeposition (Biggs 1982; Kearney et al. 1988; Kleinhans et al. 2009) and wind-driven wave action can also have strong effects (Fagherazzi and Wiberg 2008; Leonardi and Fagherazzi
2014; Priestas et al. 2015). The interaction of sea-level rise and sediment deposition rates can also cause the widening of creeks (Fagherazzi et al. 2012). However, little attention has been payed to potential enhancement of erosion due to the creation of engineered edges along channels directly cut through marshlands or into wetlands.

In this study, it was expected that the cut edges in salt marshes would be less stable and more prone to slumping and other erosional forces than natural edges under otherwise similar conditions. Secondly, it was expected that the edges would become more stable over time. This study attempts to address these questions using the test case of Hempstead Bay, Long Island, New York.

\section{Methods}

Maps, aerial photographs, bathymetry, and historical records from various sources were used to locate edges that were the result of engineering projects implemented between 1879 and 2012, as detailed below.

\section{Study Location}

The Hempstead Bay study site is on the Atlantic Coast of North America currently includes approximately 7900 ha of wetlands and close to 2500 ha of salt marsh, mostly covered with Spartina alterniflora (Fig. 1). These wetlands are typically grouped into the West Bay, Middle Bay, and East Bay. These bays lack distinct river deltas, but have meander streams with point bars and the sediments range from fine-

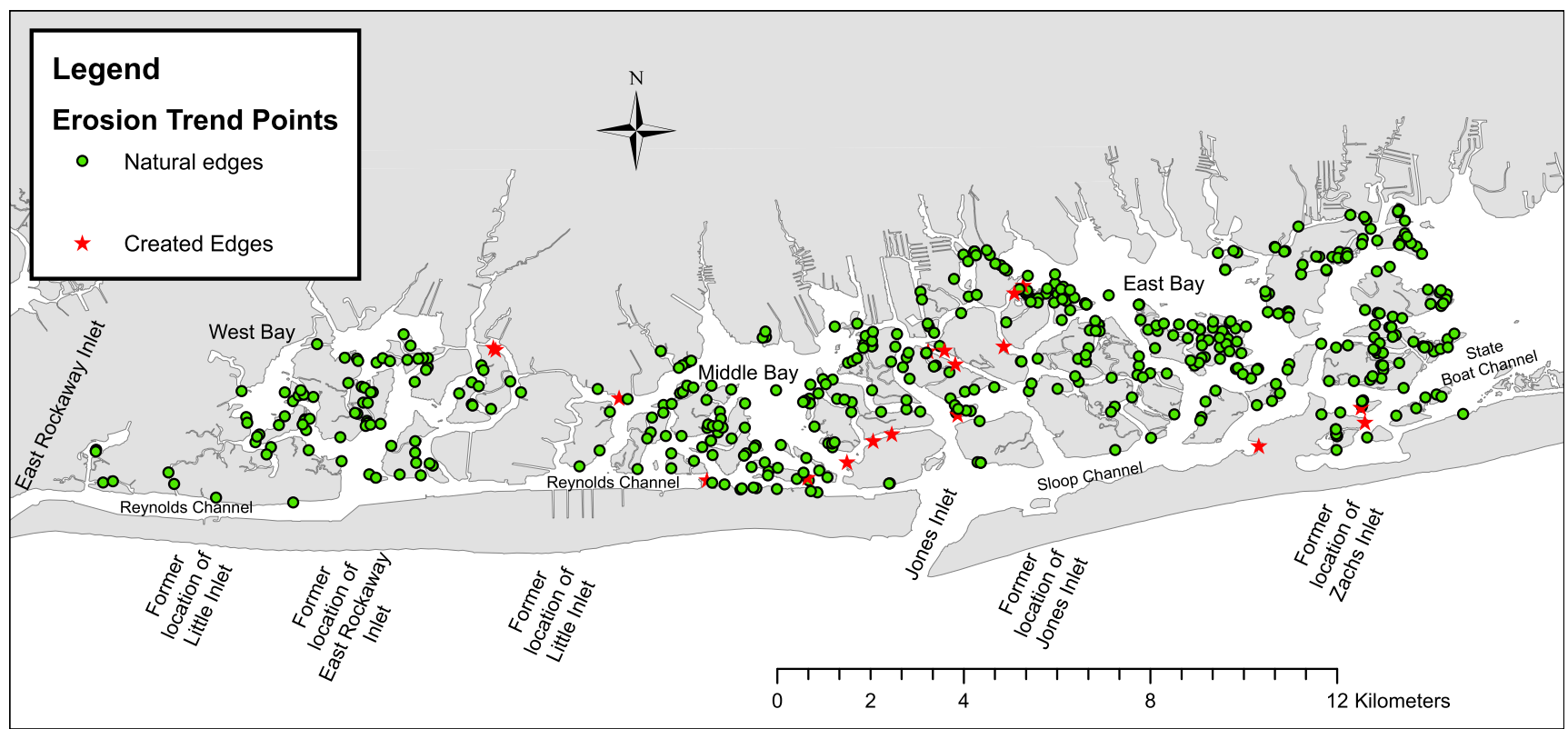

Fig. 2 A map of the study area and the points located randomly along the shoreline; points represented by stars indicate channelized edges 
Table 1 Navigational channels. This variable was a categorical variable, whose rank was subjectively determined, and included waterways marked or formerly marked with navigational aids and charted on NOAA navigational charts 12352 (see Electronic Supplemental Material for more detail)

\begin{tabular}{|c|c|}
\hline Category & Criterion \\
\hline A & $\begin{array}{l}\text { Many large boats, including commercial traffic up to } 100 \mathrm{~m} \\
\text { at water line (LWL), use the Inland Waterway and Long } \\
\text { Creek channels to Jones and East Rockaway inlets. } \\
\text { Commercial traffic including coastal tankers, coastal } \\
\text { fishing boats, party boats, ocean-going charter boats, and } \\
\text { casino boats used them. Maintenance dredging of these } \\
\text { channels was performed as needed by federal or state } \\
\text { agencies. Peak use could exceed } 60 \text { boats per hour. }\end{array}$ \\
\hline $\mathrm{B}$ & $\begin{array}{l}\text { Many boats, some large commercial traffic as defined for A. } \\
\text { These were secondary channels that feed from significant } \\
\text { concentrations of marinas and wharfs into the A channels. } \\
\text { Occasional town maintenance dredging of these channels } \\
\text { was performed if needed to allow navigation. Peak use } \\
\text { could approach } 60 \text { boats per hour. }\end{array}$ \\
\hline $\mathrm{C}$ & $\begin{array}{l}\text { These had frequent small and medium boat traffic. Peak use } \\
\text { was about } 20 \text { boats per hour with boats up to about } 8 \mathrm{~m} \\
\text { AWL. These were smaller tertiary channels that mostly } \\
\text { fed into B channels from smaller subsets of marinas. }\end{array}$ \\
\hline $\mathrm{D}$ & $\begin{array}{l}\text { Local use channels, which were mostly interconnecting side } \\
\text { channels connecting between B and C channels, or they } \\
\text { only fed residential docks. Small boats to about } 8 \mathrm{~m} \text { LWL } \\
\text { used them, with peak use to about } 10 \text { boats per hour. Most } \\
\text { were marked as } 5 \text { mile } \mathrm{h}^{-1}\left(8 \mathrm{~km} \mathrm{~h}^{-1}\right) \text { zones. }\end{array}$ \\
\hline $\mathrm{E}$ & $\begin{array}{l}\text { Low local use channels were small side channels feeding } \\
\text { traffic from only a small number of houses or bay leases } \\
\text { into more heavily used channels. Navigational aids and } \\
\text { maintenance dredging may have been discontinued due to } \\
\text { low traffic level. Typically, there were only up to about } \\
2-3 \text { boats per hour. }\end{array}$ \\
\hline $\mathrm{X}$ & $\begin{array}{l}\text { Not official navigational water. These waters include all of } \\
\text { the remaining marsh edges. Widths and depths vary from } \\
\text { broad shallow bays to narrow drainage channels of up to } \\
3 \mathrm{~m} \text { depth below MLW. Boat use was rare to non-existent, } \\
\text { usually less than } 1-2 \text { per day, confined to local fishermen } \\
\text { in small shallow draft boats less than } 6 \mathrm{~m} \text { LWL. }\end{array}$ \\
\hline
\end{tabular}

grained sands to silts and clays. The study location is at the high end of micotidal, with a range of approximately $1.8 \mathrm{~m}$ and two cycles per day. Tidal exchange with the Atlantic Ocean flows through the East Rockaway Inlet and Jones Inlet, where both ebb-tidal and flood-tidal bars are found as is typical of tidal inlets (Biggs 1982).

Starting with colonization in the seventeenth century and continuing into the 1950s, the Hempstead Bays and their watersheds have been altered in many ways, deepened with

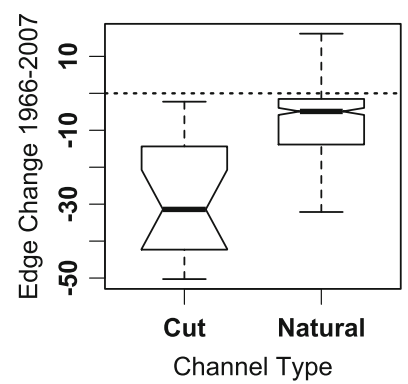

Fig. 3 The change in the location of the marsh edges between 1966 and 2007 comparing those that were channelized $(C)$ and natural edges of any other type $(N)$, with the median represented as bold lines, the boxes representing the upper and lower quartiles, whiskers represent extreme values, and a Tukey notch where the groups are likely significantly different if the notches do not overlap

borrow pits, crossed by navigational channels, and often removed when dredging supplied fill. The fill was frequently used to cover sections of salt marsh for use as roadways, housing, and industrial areas (Browne 2011).

\section{Photographic Data Sets Used in This Study}

A series of 13 sets of aerial photographs covering 86 years were used, including the years 1926, 1950, 1956, 1966, 1973, 1978, 1983 1989, 1994, 2000, 2004, 2007, and 2012. Orthoreferenced photographs were obtained from the New York State Office of Technology (NYS Department of Technology) for the years 1994-2007. NOAA Hurricane Sandy assessment images from November 2012 were also used in this study (http://storms.ngs.noaa.gov/storms/sandy/). Images of survey maps from 1879 and 1880 (US Coast and Geodetic Survey Reg. No. T-1471 and T-1538) were downloaded from the Stony Book University Library online map collection (http://digital.library.stonybrook.edu/cdm/ landingpage/collection/limaps). Data traced from these survey documents were also made available by the New York State Department of Technology. Older photography (1926-1989) were from photographic prints from the archives of the Town of Hempstead Department of Conservation and Waterways that were scanned at high resolution and then referenced to match the 2000 and 2004 ortho-photographs using Blue Marble Geographic Geographic Transformer® Version 6.0 (Blue Marble Geographics Incorporated). Aerial photography from 1956 to 1989 were prints from individual photographs from aerial

Table 2 Wilcox rank-sum test with continuity correction, for differences in salt marsh loss between 1966 and 2007 comparing edges of the marsh that were created by channelization and all natural marsh edges

\begin{tabular}{llccrrr}
\hline- & $P$ & Number & Mean change $(\mathrm{m})$ & Median (m) & SD \\
\hline Not channelized & - & 408 & -8.38 & -4.74 & 15.32 \\
Channelized & $<0.001$ & 30 & -27.52 & -23.04 & 0.76 \\
\hline
\end{tabular}



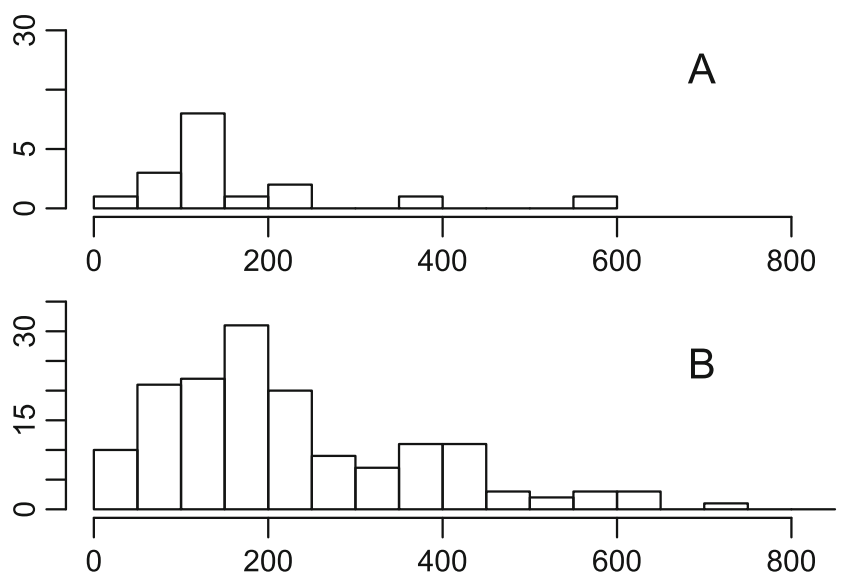

Fig. 4 A frequency distribution of 1966 widths for channelized $(A)$ and natural edged navigational channels $(B)$

surveys and referenced well to submeter accuracy. Available photography for 1926 and 1950 were re-photographed composites that had therefore lost some detail and exhibited the spherical aberrations of the component prints. Accurate referencing for the 1926 and 1950 sets required digital subsetting for the retrieval of individual images before referencing.

A reference outline of the marshland's outer edges was created from the 1994 images and 500 points were then randomly chosen along edges using a Python script (Fig.2). Measurements of change were made between the year of a photograph and the 1994 reference line and changes between various combinations of years were calculated from those measurements (Browne 2009, 2011).

The response variable for statistical tests was the change in the location of the marsh edges between specific years, with changes between 1966 and 2007 used for most comparisons. A second response variable is the annualized change in a channelized edge over the intervals between each pair of photographic sets to be regressed against the age of the edge, estimated as the time interval from the middle of each interval to the date of the oldest photo containing a particular channelized edge. Code written in R (R Development Core Team 2009) estimated the age of subsequent measurements for each sample point along channelized marsh edges, producing an approximate ages for each location the hypothesis of stabilization through time could be explored.

Boat traffic was ranked by relative levels of activity and potential wake impact on wetlands from high (A) to low (E) and none $(\mathrm{X})$, although this report does not focus on boat traffic per se (Table 1; see Electronic Supplemental Information for categorization detail). Categories of channelized edges (DT for dredged through) and natural edges were made independently.

\section{Channelized Edges}

Identification of channelized edges was primarily through historical data, derived by comparing pre- and post-construction spatial data. Channelized edges on the remaining marshes are of direct anthropogenic origin, intentionally created as part of some major construction project prior to legal protection for these wetlands. These edges were usually straight and deeply cut, marking the sharp boundary where the damage to the marsh occurred. For example, the marshlands were surveyed by the US Coast and Geodetic Survey in 1879 and 1880 provided a comparison with the photography from 1926 and later, aiding in the identification of channelized edges and the locations of older inlets.

\section{Statistics}

Statistical analysis and graphical representations of trends were done in the $\mathrm{R}$ environment ( $\mathrm{R}$ Development Core Team 2009). The response variable was in meters of marsh loss and independent variable in number of years, with these units retained to aid in interpretation of loss rates. Because the retained untransformed response variable was non-normal, non-parametric Mann-Whitney tests (aka unpaired Wilcoxon) with continuity correction for paired comparisons were performed using the wilcox.test() function in R. When multiple tests are performed that are not independent, type I error becomes more likely and false discovery rate control is required (Benjamini and Hochberg 1995). The recommendations of Benjamini and Hochberg (1995) were employed to adjust down the critical $P$ value for significance when interpreting Mann-Whitney tests. Box plots show the median as a bold horizontal line with the first and third quartiles defining the box. The "whiskers" of the box plots are defined as 1.5 times the inter-quartile range or the maximum or minimum if 1.5 range is not exceeded. Points exceeding 1.5 the interquartile range are plotted individually. Notches in box plots are calculated as plus and minus 1.58 times the inter-quartile

Table 3 Wilcox rank-sum test with continuity correction, for 1966-2007, comparing loss of marsh between channelized areas 75 to $400 \mathrm{~m}$ wide and natural marsh edges along all other waterways of the same range of widths

\begin{tabular}{llccrrr}
\hline- & $P$ & Number & Mean change $(\mathrm{m})$ & Median $(\mathrm{m})$ & SD & SE \\
\hline Not channelized & - & 177 & -10.62 & -8.98 & 1.18 \\
Channelized & $<0.001$ & 26 & -29.41 & -26.31 & 15.72 & 21.36 \\
\hline
\end{tabular}


Table 4 Wilcox rank-sum test with continuity correction for 1966-2007, comparing loss of marsh between channelized areas and natural marsh edges along navigational channels 75 to $400 \mathrm{~m}$ wide

\begin{tabular}{lllllr}
\hline- & $P$ & Number & Mean change $(\mathrm{m})$ & Median $(\mathrm{m})$ & SD \\
\hline Not channelized & - & 100 & -13.59 & -11.76 & 12.07 \\
Channelized & $<0.001$ & 25 & -30.5 & -27.98 & 1.21 \\
\hline
\end{tabular}

range divided by the square root of the number of samples and were developed by Tukey to visualize approximate significance when notches do not overlap (Crowley 2007, pp.154 157). Violin plots are box plots marking the median, upper and lower quartile of data, and Tukey notches, but also illustrate the range and the distribution of data points. Additionally, the channelized edges were mapped against 2011 bathymetry (R. Flood, Stony Brook University) to illustrate additional patterns that may explain causality. Methods used for additional supportive information, including sediment analysis and modeled tidal flows, can be found in the Electronic Supplementary Material.

\section{Results}

Edge change data from 1966 to 2007 were collected for 30 points that fell on channelized marsh edges and 408 points that fell on natural marsh edges. The change in location of the marsh edge between 1966 and 2007 for measurement points located along channels created by dredging was compared to the change observed for those points along natural marsh edge is described in Table 1. On average, the edges of marshes that were channelized retreated horizontally by $27.52( \pm 3.82) \mathrm{m}$ while those points on natural edges of marsh retreated on average $8.38( \pm 0.76) \mathrm{m}$, and these differences were highly significant using a Mann-Whitney $U$ test $(P<0.001$, $n 1=408, n 2=30$; Table 2 ). A box plot with Tukey notches

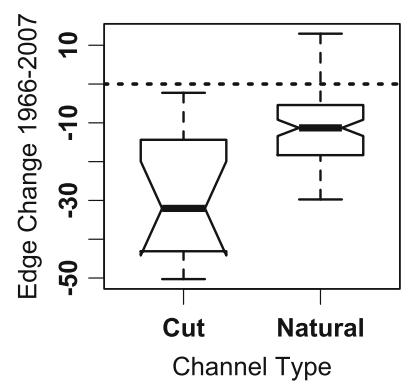

Fig. 5 The loss of marsh from channelized edges $(C)$ and natural marsh edges $(N)$ along navigational channels 75-400 m width between 1966 and 2007 represented as box and whisker plots with median values (heavy line), the upper and lower quartiles, the range (whiskers), and notches representing significant differences between groups when the notches do not overlap illustrates the large difference between channelized and natural edges (Fig. 3).

To take into account the potential influence of wind-driven waves due to waterway width, a subset of measurement points for both categories with widths within the range typical for the channelized edges (76 to $400 \mathrm{~m}$ ) was required (Fig. 4). Along these similarly sized waterways, channelized marsh edges retreated horizontally by an average of $29.41( \pm 4.19) \mathrm{m}$ while natural edges retreated on average $10.62( \pm 1.18) \mathrm{m}$ (Table 3$)$, and these differences were highly significant using a MannWhitney $U$ test $(P<0.001, n 1=177, n 2=26)$.

This analysis was repeated and was further restricted to a subset of measurement points on channelized marsh edges that were also along navigational channels so as to better control for vessel traffic. In this case, the channelized marsh edges retreated horizontally by an average of $30.05( \pm 4.21) \mathrm{m}$ while those points on natural edges of marsh facing similarly sized navigational channels retreated a mean distance of 13.59 $( \pm 1.21) \mathrm{m}$ (Table 4, Fig. 5). Again, there was a significant difference between these two groups using a Mann-Whitney $U$ test $(P<0.001, n 1=100, n 2=25)$.

To control for differing vessel use, channelized and natural edges of similar width (75-400 m across) were further subdivided by vessel use categories (Table 5) and are illustrated in a violin plot (Fig. 6). The results of Wilcox tests are in Table 6. Given the small number of measurement points for some categories, this test had relatively low power, yet significant difference were still found between the highest use channelized edges (A and B) and the lower use natural edges ( $\mathrm{B}$ through E). Marsh edges channelized between 1890 and 1966 (Fig. 2) showed higher loss rates than all categories of natural marsh edges during the same period (Fig. 7), and the loss of marsh edge over 81 years, relative to the 1994 reference edge, shows little indication that the loss of marsh from channelized edges had slowed through time (Fig. 8). Loss along channelized edges was consistently greater than natural edges of marsh along all classes of channels.

When comparing changes in marsh surface with 2011 bathymetry, it was discovered that some artificially created channels that had provided shorter routes to and from inlets for tidal flows had expanded in width beyond their original size, i.e., the Reynolds Channel (Fig. 9), State Boat Channel, and Swift Creek. Hydraulic radii for a channelized section of the Reynolds Channel had also increased and were estimated to be $1.50,4.38$, and $6.10 \mathrm{~m}$ for 1926,1950 , and 2012 , 
Table 5 Change in marsh edge from 1966 to 2007 for channelized and natural marshes along navigational channels of different boat use categories. The categories are described in Table 1. Negative numbers indicate a loss of marsh

\begin{tabular}{llllccccccc}
\hline Use & $\begin{array}{l}\text { Channelized } \\
\text { median }(\mathrm{m})\end{array}$ & Mean & Number & SD & SE & $\begin{array}{l}\text { Natural } \\
\text { median }(\mathrm{m})\end{array}$ & Mean & Number & SD & SE \\
\hline A & -30.33 & -43.68 & 6 & 33.27 & 13.58 & -15.42 & -15.89 & 16 & 13.89 & 3.47 \\
B & -31.42 & -27.51 & 11 & 14.6 & 4.4 & -10.07 & -13.73 & 19 & 11.72 & 2.69 \\
C & -13.94 & -23.02 & 3 & 17.42 & 10.06 & -11.49 & -14.02 & 26 & 15.8 & 3.10 \\
D & -22.93 & -22.93 & 2 & 9.63 & 6.81 & -12.38 & -13.9 & 23 & 7.12 & 1.48 \\
E & -21.45 & -27.62 & 3 & 20.3 & 11.72 & -7.82 & -10.00 & 16 & 9.57 & 2.39 \\
X & -2.26 & -2.26 & 1 & NA & NA & -5.85 & -6.77 & 77 & 18.88 & 2.16 \\
All & -26.305 & -29.41 & 26 & 21.36 & 4.19 & -8.98 & -10.62 & 177 & 15.72 & 1.18 \\
\hline
\end{tabular}

respectively (see Electronic Supplemental Material). Sediment samples were obtained from the Reynolds Channel (Fig. 9), and grain size results were used to calculate the critical depth-averaged flows for initiation of sediment movement. When these results were compared with modeled depth-averaged peak tidal flows for each sampling location, sediment movement during peak tidal flows was found to be likely (see Electronic Supplemental Material). Other created channels that were orthogonal to tidal flow were filling (i.e., Sea Dog Creek), consistent with an interaction between the channelizing of marsh edges and the relative direction and strengths of tidal flows.

Little evidence of stabilization through time was found. The linear model regressing the annualized losses for each location against the estimated age at the time of measurement was not statistically significant and explained virtually none of the variance (Fig. 10). The relative lack of stabilization through time is also demonstrated by comparing the median annualized rates for edges with less than 40 years of recovery since channelization $\left(-0.384 \mathrm{~m}\right.$ year $\left.^{-1}\right)$ to those with more than 40 years of recovery $\left(-0.359 \mathrm{~m} \mathrm{year}^{-1}\right)$, results that are virtually identical.

\section{Discussion}

This study confirmed that channelized edges of marshes can have significantly more erosion than channels retaining natural edges, even after accounting for boat traffic. Within the study site, 16.5 ha of marsh were lost along these channelized
Fig. 6 Violin plot containing box plots showing the upper and lower quartile and a median line and then surrounded by the distribution of the loss of marsh from 1966 to 2007 for channelized edges (DT) and natural edges along channels categorized by levels of boat use (high A-low E, and none X; see Table 1 and Electronically Available Supplemental Information)

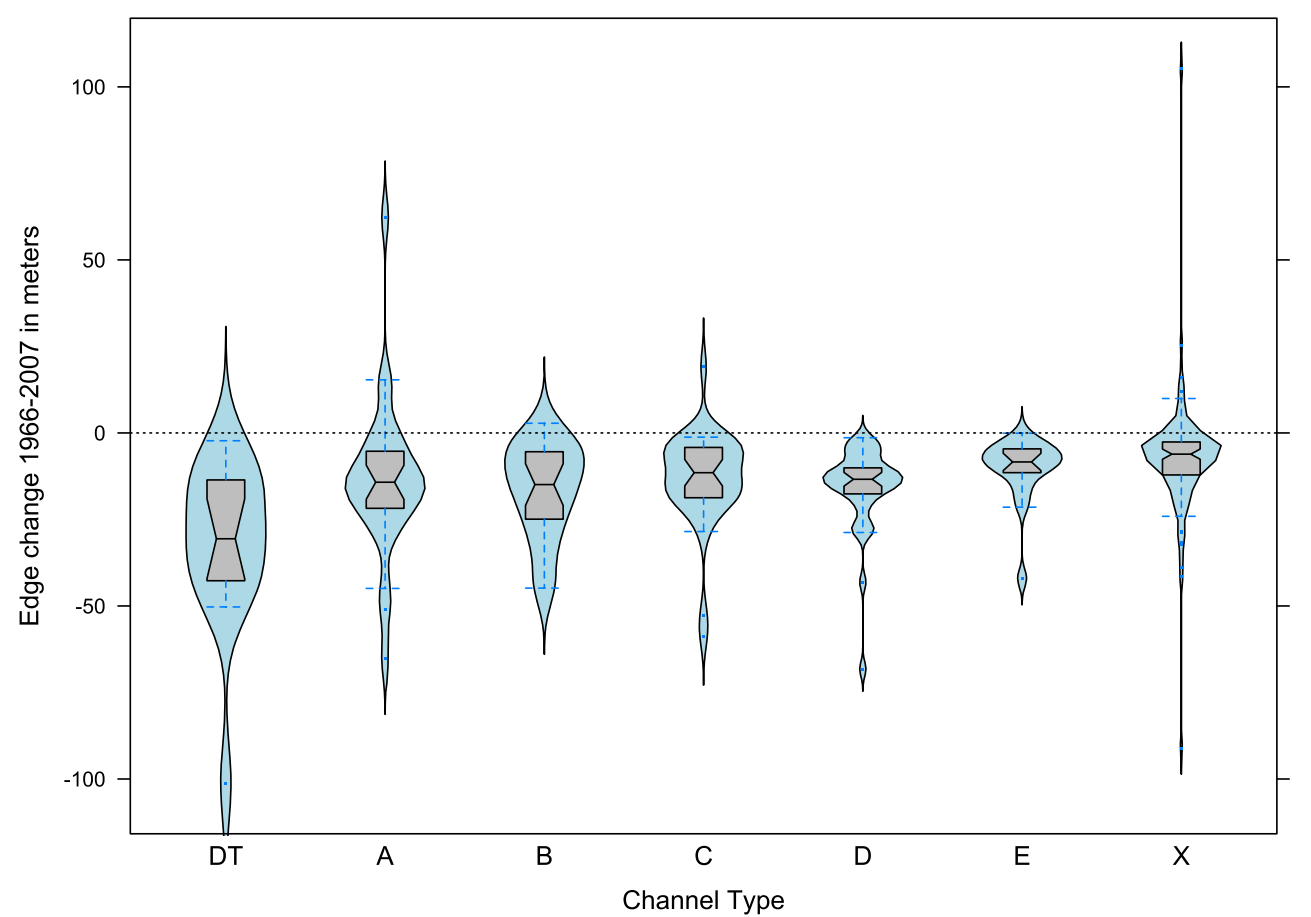


Table 6 The results of a Wilcox rank-sum test for marsh loss from 1966 to 2007 comparing channelized versus natural shores for channels 75 $400 \mathrm{~m}$ wide, when grouped by navigational channel use classification

\begin{tabular}{llllll}
\hline \multirow{2}{*}{ Channelized } & \multicolumn{4}{l}{ Natural shores } \\
\cline { 2 - 6 } & $\mathrm{A}$ & $\mathrm{B}$ & $\mathrm{C}$ & $\mathrm{D}$ & $\mathrm{E}$ \\
\hline $\mathrm{A}$ & 0.02 & $0.009^{*}$ & $0.009^{*}$ & $0.001^{*}$ & $0.001^{*}$ \\
$\mathrm{~B}$ & 0.06 & $0.015^{*}$ & $0.003^{*}$ & $0.005^{*}$ & $0.002^{*}$ \\
$\mathrm{C}$ & 0.79 & 0.36 & 0.39 & 0.35 & 0.05 \\
$\mathrm{D}$ & 0.39 & 0.24 & 0.30 & 0.08 & 0.08 \\
$\mathrm{E}$ & 0.56 & 0.16 & 0.20 & 0.28 & 0.03 \\
\hline
\end{tabular}

* Significance after using false recovery control to adjust the critical $P$ value for significance with these multiple tests (Benjamini and Hochberg 1995)

areas between 1983 and 2004. This represented a total of $15.2 \%$ of the 108.6 ha of marsh lost in the Hempstead Bay during this period, even though marsh islands possessing at least one channelized edge comprise less than $7 \%$ of the total marshland edge. Edges that were channelized retreated an average of $27.5 \mathrm{~m}$ over the 51-year period from 1966 and
2007, compared to a mean retreat of $8.4 \mathrm{~m}$ for other marsh edges. Channelized edges, therefore, lost marsh area at a rate 3.25 times faster than that seen along other types of edges. Channelized areas in the study estuary were not typically created primarily as navigation channels; however, channels created specifically for navigation in other estuaries may sustain similar or even additional impacts. Prior studies of navigational channels have focused on the effects of vessel traffic rather than the origin of the channel (e.g., Price 2006; Davis et al. 2009); thus, it is difficult to determine to what degree the rate of marsh loss documented in other studies were primarily from boat traffic or due to other influences, including lasting effects from deliberate cuts through the marsh.

Contrasting with expectation, the erosion after channelization did not seem to slow after the initial removal of marsh, but continued with higher rates for at least 50 to 80 years after the initial damage (Fig. 7). Strong tidal currents alone will drive patterns of erosion and redeposition (meanders) in tidal wetlands (Biggs 1982; Kearney et al. 1988; Kleinhans et al. 2009), resuspending and removing sediment from the marsh (Wang 2002; Larsen et al. 2009). Altered hydrology induces continuing shifts in tidal flows end river courses, and therefore neighboring wetlands, by altering sediment transport (Teal
Fig. 7 Loss of marsh edge through time for channelized marsh (DT), different degrees of boat use (A-E), and those edges not along a navigational channel (X) (see Table 1 and Electronically Available Supplemental Information for definitions)

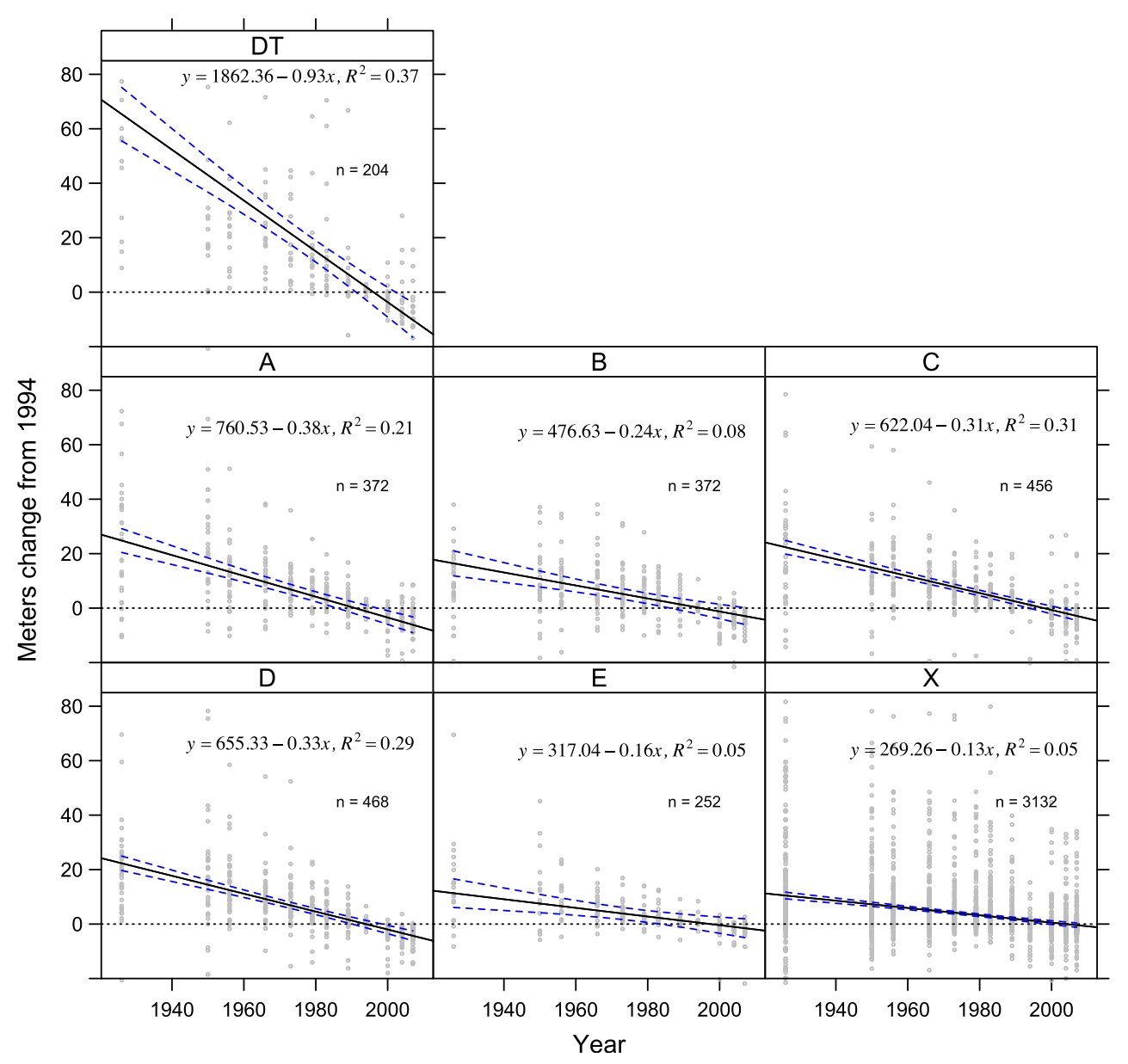




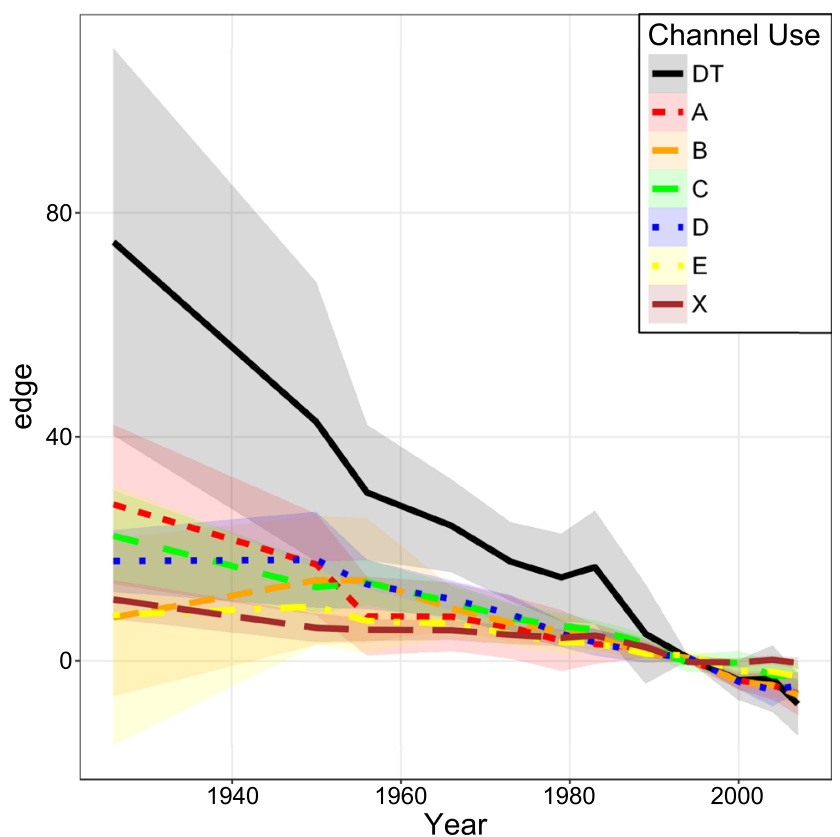

Fig. 8 Mean values of marsh edge change relative to the 1994 marsh reference line from 1926 to 2007 for marsh edges that were channelized (DT), natural marsh edges along navigational channels with different degrees of boat use (A-E), and those points neither along a navigational channel nor channelized $(\mathrm{X})$
2001; Renfro et al. 2010), and even the local tidal range may also be affected (Swanson and Wilson 2008). This study demonstrated that, at least in some cases, rerouted tidal flows may lead to accelerated sediment removal, meanders, and the growth of a created channel far beyond its original constructed cross section, leading to large continued wetland losses. Additional studies with more sample points, different tidal regimes, and longer time intervals may be needed before patterns in the deceleration of erosion rates can be fully documented along altered tidal channels.

To our knowledge, this is the first study that contrasted navigational channels that retained natural edges with those constructed with channelized edges. The degree to which the results of this study may be applied to other locations may depend on the construction of vessels and local hydrological conditions. Large cargo ships in narrow channels will create strong local displacement currents as water from ahead of the ship moves around the ship (Davis et al. 2009); back-flow effects are only noticeable if the displacement of the ship is large relative to the volume of the channel and not found with small surface planing boats. While some studies have concluded that vessel passage can cause erosion by creating short period waves and their own currents that resuspend sediment in lakes and

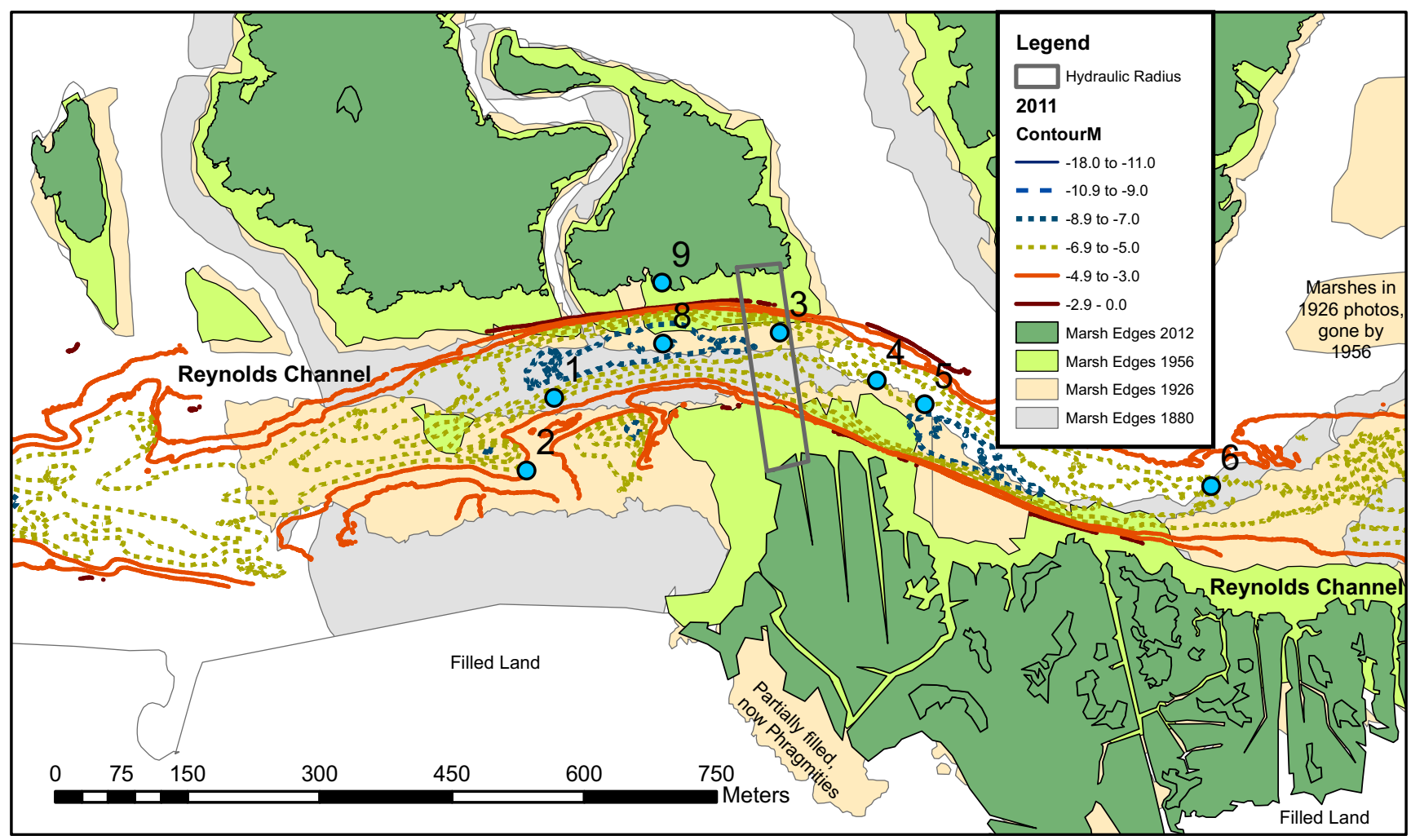

Fig. 9 An overlay of 1926, 1956, and 2012 outlines with 2011 bathymetry showing that the original narrow channel and the meander that later occurred creating depths to over $10 \mathrm{~m}$ due to tidal flows apparently resulting from the redirection of channels and also showing the numbered locations of sediment samples and the cross sectional zone used to estimate hydraulic radii 


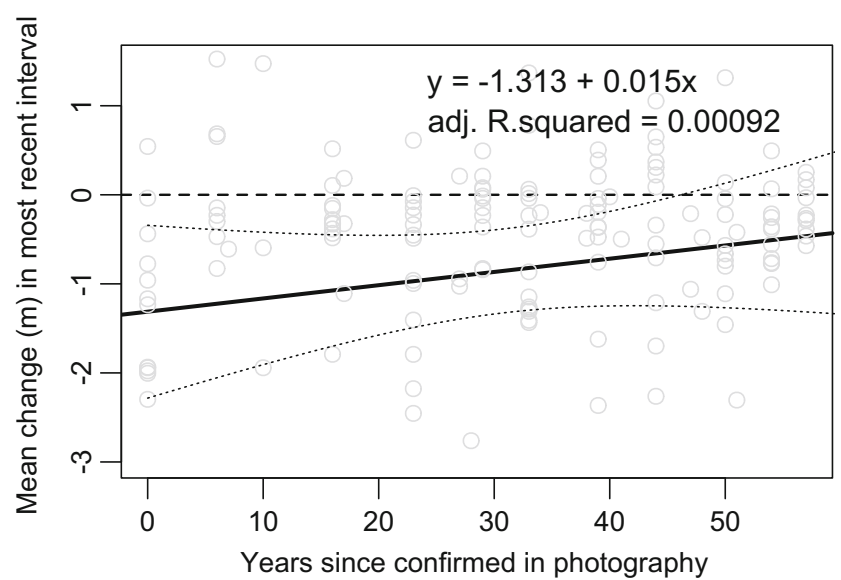

Fig. 10 A least squares fit plotting the mean annualized loss along channelized edges against the time in years after the earliest photograph showing the presence of each edge

rivers (Dorava and Moore 1997; Hofmann et al. 2008; Hofmann et al. 2011), other studies that have considered confounding factors have concluded that in those cases, boat use was a comparatively minor factor in the loss of marshlands (Zabawa and Ostrom 1980; Houser 2010). Management efforts focused only at reducing wakes from boats in channels may therefore fail when high water flow rates, natural meander dynamics, wind-driven waves, channelized edges, or other factors are the dominant causes of erosion.

The practice of dredging channels directly through marshlands, or into the edges of marshland, is no longer allowed in most parts of the USA; thus, new damage of this type is not expected to be widespread in future years. We suggest that wetland management programs in other locations should also take steps to prevent this type of damage to valuable marshes. However, the results of this study indicated that simple legal protection from additional new damage to marsh edges was insufficient for stemming marsh loss from channels that were cut decades ago. Efforts to slow or stop the continued loss of marsh areas that have been channelized in the past will likely require new stabilization or restoration methods wherever the cutting of channels through wetlands has occurred.

Acknowledgments I particularly want to thank Dianna Padilla for her help and support through this work and Ronald Masters for his support when applying for grants and implementing the data collection. People who have contributed their effort and skills directly to this project by assisting with referencing photographs and mapping the edges include Jonathan Ciappetta, Richard Chlystun, Rory Eblen, Karen Eichelburger, Elizabeth Gonzales, Margaret Gotsch, Ryan Mayer, Kevin Medrano, Alexander Mintz, Kerry Muldoon, Stephen Naham, Tina Scharf, Sharon Sclafani, and Kenneth Ullrich. Thanks to Jeffery Herter of the New York Department of State Division of Coastal Resources for the use of traced outlines from the Coast and Geodetic survey maps 1471b, 1538a, and 1538b. Thanks to Dr. Roger Flood, Stony Brook University School of Marine and Atmospheric Science (SoMAS), for the use of his 2011 bathymetry, Charles Flagg and Robert Wilson, also from Stony Brook University SoMAS, for the use of results from their Great South Bay hydrological modeling project. Partial funding was provided by the
New York Department of State Division of Coastal Resources for matching grant no. T006429 for a trends analysis of the salt marshes within Hempstead Bay awarded to and matched by the Town of Hempstead Department of Conservation and Waterways. We would also like to thank the anonymous reviewers for their helpful suggestions.

Open Access This article is distributed under the terms of the Creative Commons Attribution 4.0 International License (http:// creativecommons.org/licenses/by/4.0/), which permits unrestricted use, distribution, and reproduction in any medium, provided you give appropriate credit to the original author(s) and the source, provide a link to the Creative Commons license, and indicate if changes were made.

\section{References}

Alber, Merryl, Erick M. Swenson, Susan C. Adamowicz, and Irving A. Mendelssohn. 2008. Salt marsh dieback: An overview of recent events in the US. Estuarine, Coastal and Shelf Science 80: 1-11.

Barbier, Edward B., Sally D. Hacker, Chris Kennedy, Evamaria W. Koch, Adrian C. Stier, and Brian R. Silliman. 2011. The value of estuarine and coastal ecosystem services. Ecological Monographs 81: 169-193.

Benjamini, Yoov, and Yosef Hochberg. 1995. Controlling the false discovery rate: A practical and powerful approach to multiple testing. Journal of the Royal Statistical Society 1: 289-300.

Biggs, Robert B. 1982. Estuaries. In The encyclopedia of beaches and coastal environments, ed. M.L. Schwartz, 393-397. Stroudsburg: Hutchinson Ross Publishing Company.

Browne, J.P. 2009. A new approach for quantifying losses and gains in Spartina marshes. Paper presented at: Estuaries and Coasts in a Changing World, Coastal and Estuarine Research Federation 20th Biennial Conference, Portland, Oregon, USA.

Browne, J.P. 2011. Impacts on Spartina alterniflora: Factors affecting salt marsh edge loss. Ph.D. dissertation, Stony Brook University, New York, USA.

Cooper, Nicholas J. 2005. Wave dissipation across intertidal surfaces in the Wash Tidal Inlet, Eastern England. Journal of Coastal Research 21: $28-49$.

Costanza, Robert, Perez-Maqueo Octavio, M. Luisa Martinez, Paul Sutton, Sharolyn J. Anderson, and Kenneth Mulder. 2008. The value of coastal wetlands for hurricane protection. Ambio 37: 241-248.

Crowley, M.J. 2007. The R book. John Wiley and Sons Ltd., The Atrium, Southern Gate, Chichester, England, 950 pp.

Davis, Stephan E., John Brian Allison, Matthew J. Driffill, and Saijin Zhang. 2009. Influence of vessel passages on tidal creek hydrodynamics at Arkansas National Wildlife Refuge (Texas, United States): Implications on materials exchange. Journal of Coastal Research 25: 359-365. doi:10.2112/07-0946.1

Deegan, Linda A., Jennifer L. Bowen, Deanne Drake, John W. Fleeger, Carl T. Friedrichs, Kare A. Galvan, John E. Hobbie, Charles Hopkinson, David Samuel Johnson, J. Michael Johnson, Lynsey E. LeMay, Erin Miller, Bruce J. Peterson, Christian Picard, Sallie Sheldon, Michael Sutherland, Joseph Vallino, and R. Scott Warren. 2007. Susceptibility of salt marshes to nutrient enrichment and predator control. Ecological Applications, Supplement 17: S42-S63.

Deegan, Linda A., David Samuel Johnson, R. Scott Warren, Bruce J. Peterson, John W. Fleeger, Sergio Fagherazzi, and Wilfred M. Wolheim. 2012. Coastal eutrophication as a driver of salt marsh loss. Nature 490: 388-392.

Dorava, Joseph M. and Gayle W. Moore. 1997. Effects of boatwakes on streambank erosion Kenai River, Alaska. USGS Water-Resources Investigations Report 97-4105, Anchorage, Alaska. Available via: http://pubs.usgs.gov/wri/1997/4105/report.pdf

Edwards, Keith R., Steven E. Travis, and C. Edward Proffitt. 2005. Genetic effects of a large-scale Spartina alterniflora (smooth 
cordgrass) dieback and recovery in the northern Gulf of Mexico. Estuaries 28: 204-214.

Fagherazzi, S., M.L. Kirwin, S.M. Mudd, G.R. Guntenspergen, S. Temmerman, A. D'Alpaos, J. van de Koppel, J.M. Rybczyk, E. Reyes, C. Craft, and J. Clough. 2012. Numerical models of salt marsh evolution: Ecological, geomorphic, and climatic factors. Reviews of Geophysics 50: 1-25. doi:10.1029/2011RG000359.

Fagherazzi, S. 2014. Storm-proofing with marshes. Nature Geoscience 7: 701-702. doi: 10.1038/ngeo2262 .

Fagherazzi, S., and P.L. Wiberg. 2008. Importance of wind conditions, fetch, and water levels on wave-generated shear stresses in shallow water. Journal of Geophysical Research 114 (F03022): 1-12.

Feagin, Rusty A., M. Luisa Martinez, Gabriela Mendoza-Gonzalez, and Robert Costanza. 2010. Salt marsh zonal migration and ecosystem service change in response to global sea level rise: a case study from an urban region. Ecology and Society 15. Available via: http://www. ecologyandsociety.org/vol15/iss4/art14/.

Gedan, Keryn B., Andrew H. Altieri, and Mark D. Bertness. 2011. Uncertain future of New England salt marshes. Marine Ecology Progress Series 434: 229-237.

Hofmann, Hibner, Andreas Lorke, and Frank Peeters. 2008. The relative importance of wind and ship waves in the littoral zone of a large lake. Limnology and Oceanography 53: 368-380.

Hofmann, Hibner, Andreas Lorke, and Frank Peeters. 2011. Wind and ship-induced resuspension in the littoral zone of a large lake. Water Resources Research 47: 1-12. doi:10.1029/2010WR010012/2011.

Houser, C. 2010. Relative importance of vessel-generated and wind waves to salt marsh erosion in a restricted fetch environment. Journal of Coastal Research 26: 230-240.

Kearney, Michael S., Russell E. Grace, and J. Court Stevenson. 1988. Marsh loss in Nanticoke estuary, Chesapeake Bay. The Geographical Review 78: 205-220.

Keddy, P.A., L.H. Frazer, A.I. Solomeshch, W.J. Junk, D.R. Campbell, M.T.K. Arroyo, and C.J.R. Aloho. 2009. Wet and wonderful: The worlds largest wetlands are conservation priorities. Bioscience 59: 39-51.

Kleinhans, Maarten G., Filip Schuurman, Wiecher Bakx, and Henk Markies. 2009. Meandering channel dynamics in highly cohesive sediment on an intertidal mud flat in the Westerschelde estuary, the Netherlands. Geomorphology 105: 261-276.

Larsen, Laurel G., Judson W. Harvey, and John P. Crimaldi. 2009. Predicting bed shear stress and its role in sediment dynamics and restoration potential of the Everglades and other vegetated flow systems. Ecological Engineering 35: 1773-1785.

Leonardi, N., and S. Fagherazzi. 2014. How waves shape salt marshes. Geology 42: 887-890.

Leonardi, Nicoletta, Neil K. Ganju, and Sergio Fagherazzi. 2016. A linear relationship between wave power and erosion determines salt-marsh resilience to violent storms and hurricanes. PNAS 113: 64-68. doi: 10.1073/pnas. 1510095112

McKee, Karen L., Irving A. Mendelssohn, and Michael D. Materne. 2004. Acute salt marsh dieback in the Mississippi River deltaic plain: A drought-induced phenomenon? Global Ecology and Biogeography 13: 65-73.

Mendelssohn, Irving A., and Karen L. McKee. 1988. Spartina alternifiora dieback in Louisiana: Time-course investigation of soil waterlogging effects. Journal of Ecology 76: 509-521.

Mendelssohn, Irving A., Karen L. McKee, Mark W. Heste, Qianxin Lin, Tommy McGinnis, Jonathan Willis. 2006. Brown Marsh Task II1: integrative approach to understanding the causes of salt marsh dieback - determination of salt marsh species tolerance limits to potential environmental stressors. Report submitted to the Louisiana Department of Natural Resources, Baton Rouge, Louisiana.

Möller, Iris, Thomas Spencer, Jon R. French, D.J. Leggert, and Malcolm Dixon. 1999. Wave transformation over salt marshes: A field and numerical modeling study from North Norfolk, England. Estuaries, Coast, and Shelf Science 49: 411-420.

Ogburn, Matthew Bryan, and Merryl Alber. 2006. An investigation of salt marsh dieback in Georgia using field transplants. Estuaries and Coasts 29: 54-62.

Price, Franklin D. 2006. Quantification analysis and management of intracoastal waterway channel margin erosion in the Guana Tolomato Matanzas National Estuarine Research Reserve, Florida. National Estuarine Research Reserve. Technical Report Series 2006:1. Available via: http://coast.noaa.gov/data/docs/nerrs/ Research_TechSeries_TechSeries200601.pdf

Priestas, A.M., G. Mariotti, N. Leonardi, and S. Fagherazzi. 2015. Coupled wave energy and erosion dynamics along a salt marsh boundary, Hog Island Bay, Virginia, USA. Journal of Marine Science and Engineering 3: 1041-1065.

Pye, Kenneth. 1995. Controls on long-term saltmarsh accretion and erosion in the Wash, Eastern England. Journal of Coastal Research 11: 337-356.

R Development Core Team (2009) R: A language and environment for statistical computing. R Foundation for Statistical Computing, Vienna, Austria, ISBN 3-900051-07-0, Available via: http:// wwwR-projectorg

Renfro, A.A., J.K. Cochran, D.J. Hirschberg, H.J. Bokuniewez, and S.L. Goodbred 2010. Natural radionuclides (234Th, 7Be, and 201Pb) as indicators of sediment dynamics in Jamaica Bay, New York. Natural Resource Technical Report NPS/NERO/NRTR-2010/324, Fort Collins, Colorado.

Schwimmer, Reed A. 2001. Rates and processes of marsh shoreline erosion in Rehoboth Bay, Delaware, U.S.A. Journal of Coastal Research 17: 672-683.

Shriver, W. Gregory, Thomas P. Hodgman, James P. Gibbs, and Peter D. Vickery. 2004. Landscape context influences salt marsh bird diversity and area requirements in New England. Biological Conservation 119: 545-553.

Silliman, Brian R., Johan von der Koppel, Mark D. Bertness, Lee E. Stanton, and Irving A. Mendelsshon. 2005. Drought, snails, and large-scale dieoff of southern US salt marshes. Science 310: 1803-1806.

Spiers, A.G. 2001. Wetland inventory: Overview at a global scale. In Wetland inventory, assessment and monitoring: practical techniques and identification of major issues, ed C.M. Finlayson, N.C. Davidson, and N.J. Stevenson, 23-30. Proceedings of Workshop 4, 2nd International Conference on Wetlands and Development, Dakar, Senegal, 8-14 November 1998. Darwin (Australia): Department of the Environment and Water Resources. Supervising Scientist Report 161.

Swanson, L., and R.E. Wilson. 2008. Increased tidal ranges coinciding with Jamaica Bay development contribute to marsh flooding. Journal of Coastal Research 24: 126-132.

Teal, J. 2001. Marsh loss in Jamaica Bay. In: The Jamaica Bay Blue Ribbon Panel Report, ed. J Tanacredi.

Wang, Xiao Hua. 2002. Tide-induced sediment resuspension and the bottom boundary layer in an idealized estuary with a muddy bed. Journal of Physical Oceanography 32: 3113-3131.

Wigand, Cathleen, Charles T. Roman, Earl Davey, Mark Stolt, Roxanne Johnson, Alana Hanson, Elizabeth B. Watson, S. Bradley Moran, Donald R. Cahoon, James C. Lynch, and Patricia Rafferty. 2014. Below the disappearing marshes of an urban estuary: Historic nitrogen trends and soil structure. Ecological Applications 24: 633-649.

Zabawa, Chris, and Chris Ostrom. 1980. Final report on the role of boat wakes in shore erosion in Anne Arundel County, Maryland. Tidewater Administration, Maryland Department of Natural Resources, Tawes State Office Building, Annapolis, Maryland. Available via: http://boatwakes.homestead.com/files/zabawa1-3.pdf

Zedler, Joy B., and Suzanne Kercher. 2005. Wetland resources: Status, trends, ecosystem services and restorability. Annual Review of Environmental Resources 30: 39-74. 